\title{
The Effectiveness of Alpha Mangostin on Kidney Physiology and Histopathology in Type II Diabetes Mellitus
}

\author{
Andreas Putro Ragil Santoso ${ }^{1, *(D)}$, Devyana Dyah Wulandari ${ }^{1}{ }^{(D)}$, Rizki Nurmalya Kardina ${ }^{2}$ (D), Devyani \\ Dyah Wulansari $^{3}$ (D), Bertha Meidiyanti ${ }^{1}$, Kintani Nisa Proborini ${ }^{1}$ \\ 1 Department of Medical Laboratory Technology, Faculty of Health, Universitas Nahdlatul Ulama Surabaya, Surabaya, \\ Indonesia \\ 2 Departement of Nutrition, Faculty of Health, Universitas Nahdlatul Ulama Surabaya, Surabaya, Indonesia \\ 3 Department of Pharmacology, Faculty of Pharmacy, University of Surabaya, Surabaya, Indonesia \\ * Correspondence: andreasprs87@unusa.ac.id (A.P.R.S);
}

Received: 4.10.2021; Revised: 12.11.2021; Accepted: 15.11.2021; Published: 10.12.2021

\begin{abstract}
The compound isolate alpha Mangostin was the most dominant compound found in the rind and trunk of the mangosteen fruit tree (Garcinia mangostana L.). Alpha Mangostin compounds have pharmacological activities, including antibacterial, antifungal, anticancer, antidiabetic, and other bioactivities. This study aims to determine the bioactivity of alpha Mangostin on kidney function and histopathology in type II diabetes mellitus. This study used an experimental research design with posttest only control group; this study used 36 rats consisting of 6 groups, namely negative control group, positive control group, standard medicine, and the treatment of lecturers alpha Mangostin 10 $\mathrm{mg} / \mathrm{kg}$ body weight, $30 \mathrm{mg} / \mathrm{kg}$ body weight, and $50 \mathrm{mg} / \mathrm{kg}$ BW. Parameters measured in this study were uric acid, BUN, creatinine, and renal histopathological evaluation. The results showed that there was a significant difference $(\mathrm{p}<0.05)$ in the examination of creatinine levels, but the BUN and uric acid did not show significant results $(\mathrm{p}>0.05)$ in each group. Observations on renal histopathology showed that alpha Mangostin could normalize damaged kidney tissue compared to positive controls. So it can be concluded that alpha Mangostin isolates in mangosteen has the potential as kidney bioactivity in type II diabetes.
\end{abstract}

Keywords: Diabetes; Alpha Mangostin; kidney function, kidney histopathology.

(c) 2021 by the authors. This article is an open-access article distributed under the terms and conditions of the Creative Commons Attribution (CC BY) license (https://creativecommons.org/licenses/by/4.0/).

\section{Introduction}

Traditional medicinal plants have been passed down from generation to generation in Indonesia; over time, scientists have developed the mangosteen fruit plant (Garcinia mangostana L.) as traditional medicine [1]. Mangosteen contains alpha Mangostin, which contains natural antioxidants, whereas the isolated compound is alpha Mangostin $(1,3,6-$ trihydroxy-7-methoxy-2,8-bis(3-methyl-2-butenyl)-9H-xanthen-9-one ) is the most dominant compound found in the rind and trunk of the mangosteen fruit tree. These compounds are known to have pharmacological activities such as antibacterial, antifungal, antidiabetic, anticancer, and several other bioactivities after optimal extraction [2,3].

Diabetes mellitus (DM) is a major global public health problem with increasing incidence and prevalence, especially in developing and newly industrialized countries. This chronic disease focuses on the serious complications associated with DM that can affect many vital organ systems, leading to more severe and irreversible pathological conditions such as 
nephropathy, retinopathy, vasculopathy, and neuropathy, cardiovascular disease, and hepatopathy. This study shows that DM is associated with several kidney disorders, which will lead to the endpoint of kidney failure in patients [4,5]. The impaired kidney function due to DM occurs in types 1 and 2, but treatment is more effective in type 2 DM [6].

Based on research conducted by Husen et al. about the antioxidant activity test of alpha Mangostin on blood urea nitrogen (BUN) levels and improvement of the histopathological structure showed that there was a significant relationship between the administration of 8 $\mathrm{mg} / \mathrm{bw}$ of alpha Mangostin on the decrease in BUN and creatinine values and the repair of cells in the kidneys [7]. Antioxidants in mangosteen through extracts that have been isolated pu increase antioxidant enzymes such as superoxide dismutase, catalase, and glutathione peroxidase and reduce oxidative stress such as malondialdehyde. Diabetes mellitus, which has complications leading to cardiovascular, neurological, liver, and kidney problems, can be improved by administering antioxidants obtained from mangosteen [8].

So far, studies on the effect of alpha Mangostin isolate compounds on kidney bioactivity in diabetic conditions have been carried out, but no specific type of diabetes has been applied. This research aimed to characterize the isolate compound Mangosteen using 13C and $1 \mathrm{H}$ NMR and to find out whether this compound had bioactivity in kidney disorders in rats model of type 2 diabetes mellitus with parameters measured were uric acid, creatinine, BUN, and kidney histopathology.

\section{Materials and Methods}

\subsection{Chemical reagent and preparation.}

This study used an experimental design with a posttest-only control group type. Based on the feeder formula, more than 4 were found, and the researchers used 5 rats for each treatment with a design of 6 groups consisting of a negative control group, a positive control group, a glibenclamide drug control group, and alpha Mangostin treatment $10 \mathrm{mg} / \mathrm{kg}$ body weight, $30 \mathrm{mg} / \mathrm{kg}$ body weight and $50 \mathrm{mg} / \mathrm{kg}$ BW. The dependent variable was the administration of alpha Mangostin 10,30 , and $50 \mathrm{mg} / \mathrm{kg} \mathrm{BW}$, while the independent variable in this study was the examination of kidney function (creatinine, uric acid, and BUN Urea and kidney histopathology.

The material used in this study was based on the research stages, namely the isolation of alpha Mangostin using a rotary evaporator, then the isolate was separated using the TLC plate method (Thin Layer Chromatography). Furthermore, in the treatment of rats, the material used is 200 gr male Wistar rats. fructose, glibenclamide, alpha Mangostin, aquadest. Examination of levels using a tube, blue tip, yellow tip, and photometer. Furthermore, the reading of histology of the kidney microtome for the preparation of preparations, while the reading of the preparations using a microscope.

\subsection{Treatment and measurement.}

The examination method was carried out in several stages; namely, the isolation of alpha Mangostin was carried out by using the TLC method. The sample is taken $10 \mathrm{mg}$ diluted with $10 \mathrm{~mL}$ of petroleum ether then separated by plate by heating at $100-105^{\circ} \mathrm{C}$ for 30 minutes, then dissolved with solvent then drained and eluted using eluent $n$-hexane:ethyl acetate $(4: 1)$ stain to be separated then observed under UV light with a wavelength of $254 \mathrm{~nm}$ and wavelength $366 \mathrm{~nm}$ [9-11]. 
The treatment of rats was carried out with the first several stages of adjustment, namely adjusting the condition of the rats for 14 days, the second stage of diabetes treatment by giving $20 \%$ fructose at a dose of $1.86 \mathrm{mg} / \mathrm{kg} \mathrm{BW}$ is carried out for 56 days and then the measurement of sugar levels After the third stage of diabetes, alpha Mangostin was administered for 14 days, after which the blood was taken for measurement of chemical levels of kidney function and surgery to determine kidney histopathology. Examination of kidney biochemical levels was carried out by measuring BUN with a wavelength of $340 \mathrm{~nm}$, then measuring creatinine with a wavelength of $546 \mathrm{~nm}$, and the last measurement, namely checking uric acid levels, the wavelength used was $546 \mathrm{~nm}$ [12-14]. Histological examination of the kidneys to measure cell damage in histology was based on the standards listed in Table $1[15,16]$.

Table 1. Cell degeneration in renal histopathology.

\begin{tabular}{c|l|c} 
Score & \multicolumn{1}{|c|}{ Rate of Change } & Damage percentage \\
\hline 0 & None & $0 \%$ \\
\hline 1 & Cells, degeneration reach $1 / 4$ of total observed & $25 \%$ \\
\hline 2 & Cells, degeneration reach $1 / 2$ of total observed & $50 \%$ \\
\hline 3 & Cells, degeneration reach $3 / 4$ of total observed & $75 \%$ \\
\hline 4 & Complete cell degeneration & $100 \%$
\end{tabular}

Data analysis in this study used multivariate ANOVA analysis to correlate variables with a maga limit of 0.05 . If $\mathrm{p}<0.05$, it is said that there is a relationship between the two variables, while $\mathrm{p}>0.05$, it is said that there is no relationship between the two variables.

\section{Results and Discussion}

\subsection{Physiological and histopathological examination.}

The study was conducted in 4 laboratories with stages consisting of 1). the isolation of alpha Mangostin was carried out in the chemical laboratory of the Universitas Nahdlatul Ulama Surabaya 2). the experimental animals were carried out in the Pharmacology laboratory of the University of Surabaya, 3). examination of creatinine, uric acid, and BUN levels at the Immunology Laboratory of Universitas Nahdlatul Ulama Surabaya and 4). reading of the results of kidney histology by dr. Prima Roosandris, Sp.PA at the Anatomical Pathology Installation of the Army Hospital Level III Brawijaya.

Table 2. Kidney Physiology Examination.

\begin{tabular}{l|c|c|c}
\multicolumn{1}{c|}{ Treatment } & Creatinine mg/dL & Uric Acid mg/dL & BUN mg/dL \\
\hline Negative Control & 0,52 & 2,44 & 18,188 \\
\hline Positive Control & 0,84 & 3,84 & 29,246 \\
\hline Glibenclamide control & 0,898 & 2,67 & 28,674 \\
\hline Alpha Mangostin 10mg/kg BW & 0,61 & 3,18 & 25,258 \\
\hline Alpha Mangostin 30mg/kg BW & 0,75 & 3,68 & 28,594 \\
\hline Alpha Mangostin 50mg/kg BW & 0,606 & 2,704 & 31,568
\end{tabular}

Based on Table 2, the average of the examination of the levels of rats treated with diabetes on creatinine levels by giving alpha Mangostin $50 \mathrm{mg} / \mathrm{kg} \mathrm{BW}$ in rats that have levels that are almost the same as negative controls, on uric acid levels, the average value is close to the value of negative control, namely the administration of glibenclamide, while the alpha Mangostin treatment was found to be lower at $50 \mathrm{mg} / \mathrm{kg} \mathrm{BW}$. On examination of BUN, urea did not show a decrease after the administration of alpha Mangostin. Analysis of histopathological microscopic can be seen in Figure 1. 


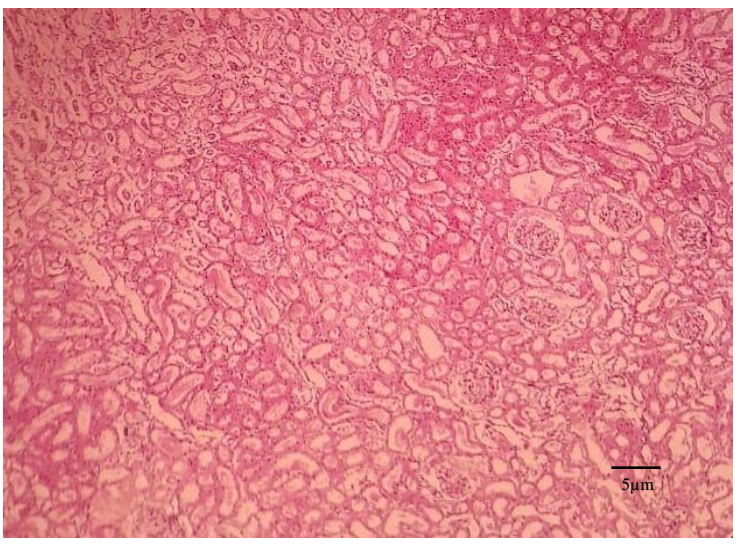

(a)

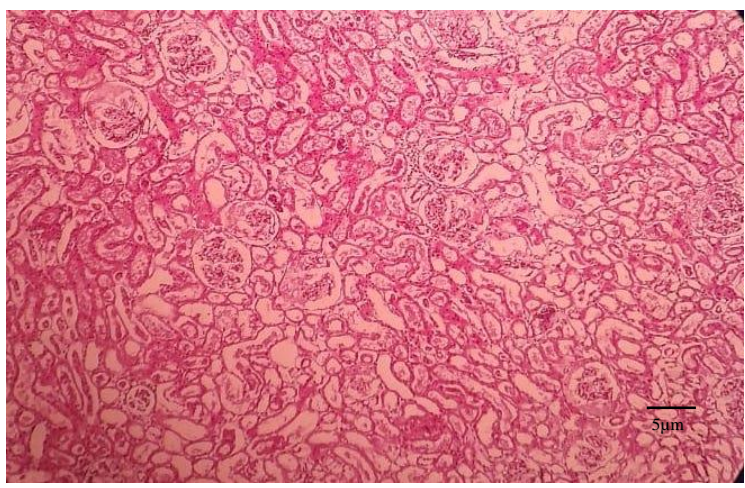

(c)

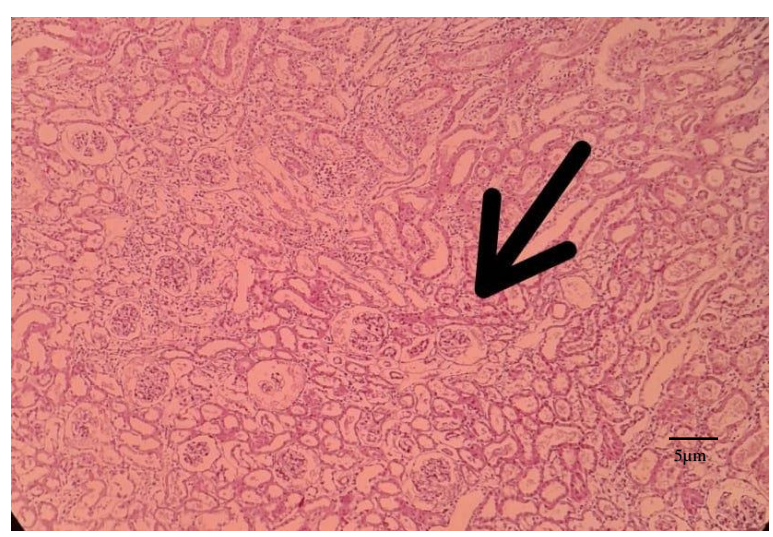

(e)

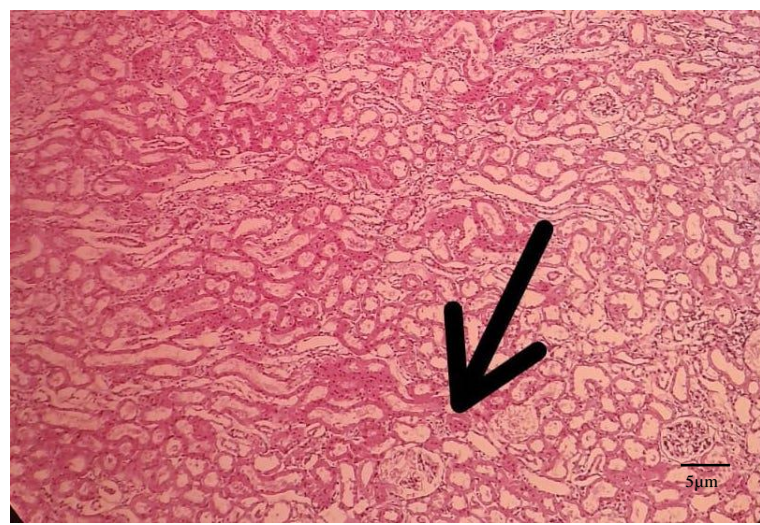

(b)

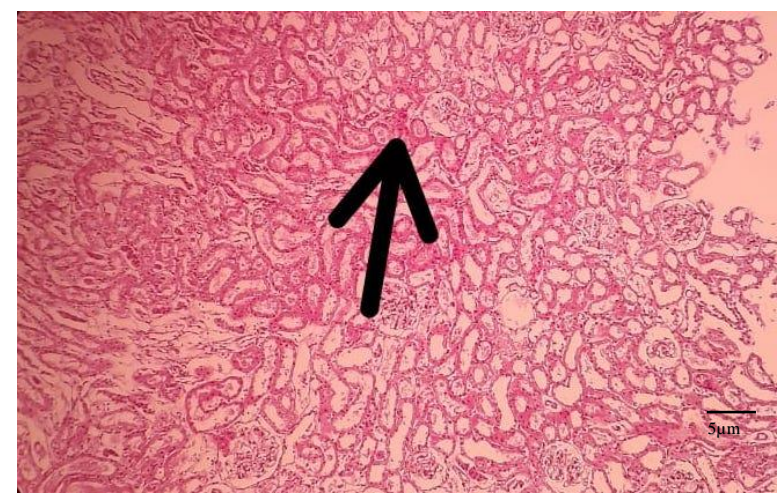

(d)

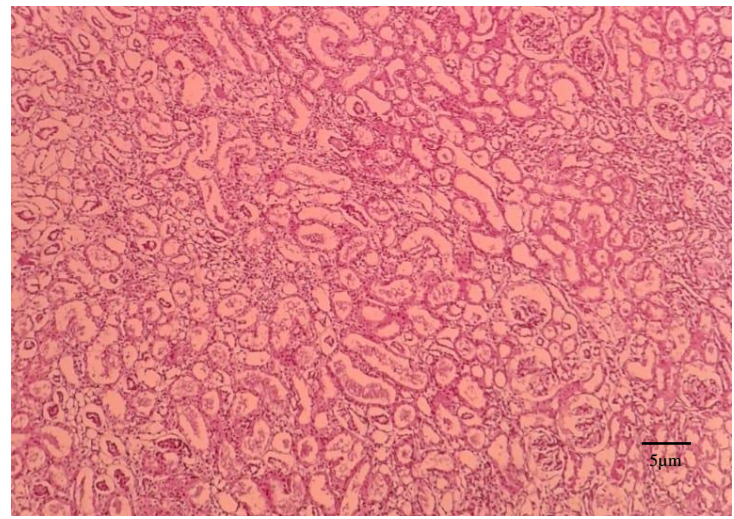

(f)

Figure 1. (a) Negative Control 0\% Figure; (b) Positive Control 10\%; (c) Glibenclamide 5\% control Figure; (d) Alpha Mangostin 10mg/kg BW 5\%; (e) Alpha Mangostin 30 mg/kgBW 5\% Figure; (f) Alpha Mangostin $50 \mathrm{mg} / \mathrm{kg} \mathrm{BW} 0 \%$.

Table 3. The ANOVA test, the chemical examination of kidney function was carried out

\begin{tabular}{l|l|c|c|c|c|c}
\multicolumn{2}{l}{} & $\begin{array}{c}\text { Sum of } \\
\text { Square }\end{array}$ & df & Mean Square & F & Sig. \\
\hline Creatinine & Between Groups & .562 & 5 & .112 & 3.656 & .013 \\
\hline & Within Groups & .738 & 24 & .031 & & \\
\hline & Total & 1.300 & 29 & & & \\
\hline Uric Acid & Between Groups & 8.512 & 5 & 1.703 & 2.573 & .053 \\
\hline & Within Groups & 15.877 & 24 & .662 & & \\
\hline & Total & 24.389 & 29 & & & .033 \\
\hline & Between Groups & .308 & 5 & .308 & & .872 \\
\hline & Within Groups & 18.499 & 24 & 9.249 & &
\end{tabular}


Based on observations, it was found that there was an improvement in cells in stages after giving alpha Mangostin to rats treated with diabetes both at $10 \mathrm{mg} / \mathrm{kg} \mathrm{BW}, 30 \mathrm{mg} / \mathrm{kg} \mathrm{BW}$, and $50 \mathrm{mg} / \mathrm{kg} \mathrm{BW}$, which was seen based on positive control damage $10 \%$ while the administration of alpha Mangostin $50 \mathrm{mg} / \mathrm{kg}$ body weight no damage.

The test in Table 3 shows an effect on creatinine levels as indicated by sig 0.013 , which means $\mathrm{p}<0.05$, which means that there is an effect of giving alpha Mangostin to rats treated with diabetes on creatinine levels. However, the BUN and uric acid showed that the sig value indicated no effect on the Uric Acid examination, which was 0.05, and on the BUN examination 0.872 , which means $p>0.05$, it means that there is no effect of giving alpha Mangostin levels to rats treated with diabetes on BUN examination and Gout.

\begin{tabular}{l|l|c|c|c|c|c}
\multicolumn{7}{|c}{ Table 4. Kidney histopathological ANOVA test. } \\
& & Sum of Square & df & $\begin{array}{c}\text { Mean } \\
\text { Square }\end{array}$ & F & Sig. \\
\hline Renal Histopathology & Between Groups & 510.268 & 5 & 102.5053 & 31.726 & .000 \\
\hline & Within Groups & 77.200 & 24 & 3.217 & & \\
\hline & Total & 587.467 & 29 & & &
\end{tabular}

The test in Table 4 shows an effect of giving alpha Mangostin on kidney histopathology in rats treated with diabetes indicated by sig. 0.000 , which means $p<0.05$, there is an effect of alpha Mangostin on kidney histopathology.

\subsection{Alpha Mangostin isolation.}

Isolation of alpha Mangostin was carried out by evaporation because the method of taking alpha Mangostin compounds would greatly affect the compounds obtained from the mangosteen rind. Alpha Mangostin obtained in this study is a compound obtained based on the extraction results followed by using the isolate by monitoring the TLC method. In taking the compound alpha Mangostin on the skin of the mangosteen fruit using the TLC method. The TLC method was also performed in isolation of alpha Mangostin [17,18].

However, it is different from other studies that have been carried out to separate alpha Mangostin using gravity column chromatography and radial system chromatography by analyzing UV-Vis, FT-IR, H-NMR, and C-NMR spectra on wood extract and root bark of Garcinia Tetranda Pierre. Based on research that has been carried out previously, the isolation of alpha Mangostin in this study was carried out using the TLC method, while apart from the mangosteen rind, other methods could be used to separate the compound so that the compound could be extracted optimally [19-21].

\subsection{Effect of alpha Mangostin on kidney function.}

The results showed that based on blood chemistry measurements, the effect of giving alpha Mangostin in diabetic rats on kidney function was different for measuring creatinine, uric acid, and BuN. In the results of creatinine levels, it was found that there was an effect of giving alpha Mangostin on creatinine levels. The creatinine results in this study are supported by research conducted by previous researchers, which showed a decrease in plasma creatinine levels in diabetic mice with a dose of $8 \mathrm{mg} / \mathrm{kg} \mathrm{BW}$ [7].

The results of uric acid and BUN levels in this study showed no effect of alpha Mangostin administration. However, this is different from research conducted by previous researchers on the antioxidant test of alpha Mangostin on BUN levels, which showed that there was an effect of giving alpha Mangostin at a dose of $8 \mathrm{mg} / \mathrm{kg} \mathrm{BW}$. Antioxidants are good for 
their antioxidant properties that can neutralize and fight free radicals to repair the damage in the body [7,22]. This study showed different results because the treatment time was short, namely 14 days.

\subsection{Effect of alpha Mangostin on liver histopathology.}

Rats with diabetes conditions can cause cell necrosis or damage to kidney cells, so giving alpha Mangostin can help repair these cells. This is indicated by the results of statistical tests showing an effect of giving alpha Mangostin on kidney histopathology results in rats treated with diabetes. The greater the alpha Mangostin gave, the better the cell proliferation as indicated by the administration of $50 \mathrm{mg} / \mathrm{kg} \mathrm{BW}$ to the sample, which is $0 \%$; it shows that the improvement occurred due to the administration of alpha Mangostin. Necrosis of cell damage caused by degeneration and loss of blood supply is characterized by cell swelling and tissue dysfunction due to damage to an organ [7,23].

Previous research by administering mangosteen rind extract provided a renoprotective effect as indicated by improvements in renal tubular cells. So it can be shown that alpha Mangostin, which has natural antioxidant and anti-inflammatory properties present in the mangosteen rind, can inhibit inflammation and oxidative stress to prevent further damage and help repair damaged cells [24-26].

\section{Conclusions}

Examination of blood chemistry on kidney function in rats treated with diabetes obtained results based on the ANOVA test on chemical examination of kidney function, which showed that there was an effect of administration of alpha Mangostin on creatinine as indicated by sig 0.013 or $p<0.05$, while on examination the levels of BUN and uric acid were not there was an effect of giving alpha Mangostin as indicated by sig 0.053 on uric acid and 0.872 on BUN or $\mathrm{p}>0.05$. And the histological examination of the kidneys in diabetic-treated rats showed the effect of alpha Mangostin administration as indicated by the results of the ANOVA test with sig. 0.000 or $\mathrm{p}<0.05$.

\section{Funding}

This reasearch was funded by Universitas Nahdlatul Ulama Surabaya.

\section{Acknowledgments}

The authors thank the Lembaga Penelitian dan Pengabdian Kepada Masyarakat with contract number:/UNUSA/Adm-LPPM/III/2021, Universitas Nahdlatul Ulama Surabaya, which supported the research in the form of funds and the use of laboratories as research facilities, the University of Surabaya pharmacy laboratory, which facilitates the treatment of rats and dr. Prima Roosandris Sp.PA, who helped read histology preparations.

\section{Conflicts of Interest}

The authors declare no conflict of interest. 


\section{References}

1. Ansori, A.N.M.; Fadholly, A.; Hayaza, S.; Susilo, R.J.K.; Inayatillah, B.; Winarni, D.; Husen, S.A. A review on medicinal properties of mangosteen (Garcinia mangostana L.). Research Journal of Pharmacy and Technology 2020, 13, 974-982, https://doi.org/10.5958/0974-360X.2020.00182.1.

2. Ghasemzadeh, A.; Jaafar, H.Z.E.; Baghdadi, A.; Tayebi-Meigooni, A. Alpha-Mangostin -rich extracts from mangosteen pericarp: optimization of green extraction protocol and evaluation of biological activity. Molecules 2018, 23, 1-16, https://doi.org/10.3390/molecules23081852.

3. Kuswahyuning, R.; Lesmana I. Formulation and evaluation of mangosteen (Garcinia mangostana L.) fruit pericarp extract gel. J Kef Indonesia 2021, 11, 90-97, https://doi.org/10.22435/jki.v11i2.3701.

4. Diabetes Canada Clinical Practice Guidelines Expert Committee; Punthakee, Z.; Goldenberg, R.; Katz, P. Definition, classification and diagnosis of diabetes, prediabetes and metabolic syndrome. Can J Diabetes 2018, 42, S10-S15, https://doi.org/10.1016/j.jcjd.2017.10.003.

5. Irene, G.; Kuswinarti, K.; Kusumawati, M. Understanding patients with type 2 diabetes mellitus using oral antidiabetic drugs. J Med Heath 2020, 2, 61-75, https://doi.org/10.28932/jmh.v2i5.1110.

6. Nordheim, E.; Jenssen, T.G. Chronic kidney disease in patients with diabetes mellitus. Endocr Connect 2021, 10, R151-R159, https://doi.org/10.1530/EC-21-0097.

7. Husen, S.A.; Firas, K.; Ansori, A.N.M.; Susilo, R.J.K.; Winarni, D. Antioxidant activity assay of alphaMangostin for amelioration of kidney structure and function in diabetic mice. Adv Soc Sci Ed Humanit Res 2017, 98, 84-88, https://doi.org/10.2991/icpsuas-17.2018.20.

8. Elmund, B.; Hartrianti, P. Evaluation of mangosteen (Garcinia mangostana) antioxidant activity in clinical trials and in vivo animal studies: A systematic review. Journal of Applied Pharmaceutical Science 2020, 10, 114-129, https://doi.org/10.7324/JAPS.2020.101216.

9. Fasya, A.S.; Amalia, S.; Megawati, D.S.; Salima, F.; Kusuma, V.A.; Purwantoro, B. Isolation, identification, and bioactivity of steroids isolates from Hydrilla verticillata petroleum ether fraction. Environ Earth Sci 2020, 456, 1-8, https://doi.org/10.1088/1755-1315/456/1/012009.

10. Wu, T.-T.; Chen, Y.-Y.; Ho, C.-Y.; Yeh, T.-C.; Sun, G.-C.; Tseng, C.-J.; Cheng, P.-W. 3H-1,2-Dithiole-3Thione Protects Lens Epithelial Cells against Fructose-Induced Epithelial-Mesenchymal Transition via Activation of AMPK to Eliminate AKR1B1-Induced Oxidative Stress in Diabetes Mellitus. Antioxidants 2021, 10, 1-14, https://doi.org/10.3390/antiox10071086.

11. Mahesh, M.; Pandey, H.; Raja Gopal Reddy, M.; Prabhakaran Sobhana, P.; Korrapati, D.; Uday Kumar, P.; Vajreswari, A.; Jeyakumar, S.M. Carrot Juice Consumption Reduces High Fructose-Induced Adiposity in Rats and Body Weight and BMI in Type 2 Diabetic Subjects. Nutrition and Metabolic Insights 2021, 14, 112, https://doi.org/10.1177/11786388211014917.

12. Imamura, Y.; Mawatari, S.; Oda, K.; Kumagai, K.; Hiramine, Y.; Saishoji, A.; Kakihara, A.; Nakahara, M.; Oku, M.; Hosoyamada, K.; Kanmura, S.; Moriuchi, A.; Miyahara, H.; Akio, i. Changes in body composition and low blood urea nitrogen level related to an increase in the prevalence of fatty liver over 20 years: A crosssectional study. Hepatology Research 2021, 51, 570-579, https://doi.org/10.1111/hepr.13631.

13. Chung, J.; Hur, M.; Cho, H.; Bae, J.; Yoon, H.-K.; Lee, H.-J.; Jeong, Y.H.; Cho, Y.J.; Ku, J.H.; Kim, W.H. The Effect of Remote Ischemic Preconditioning on Serum Creatinine in Patients Undergoing Partial Nephrectomy: A Randomized Controlled Trial. J Clin Med 2021, 10, 1-14, https://doi.org/10.3390/jcm10081636.

14. Koto, R.; Nakajima, A.; Horiuchi, H.; Yamanaka, H. Factors associated with achieving target serum uric acid level and occurrence of gouty arthritis: A retrospective observational study of Japanese health insurance claims data. Pharmacoepidemiol Drug Saf 2021, 30, 157-168, https://doi.org/10.1002/pds.5127.

15. Mao, X.; Wang, C.; Xu, Z.; He, Y.; Hou, Y.; Li, B. A novel standardized method of renal biopsy in mice. Kidney Dis 2021, 7, 306-314, https://doi.org/10.1159/000513354.

16. Su, H.; Yang, M.; Wan, C.; Yi, L.X.; Tang, F.; Zhu, H.Y.; Yi,F.; Yang, H.C.; Fogo, A.B.; Nie, X.; Zhang, C. Renal histopathological analysis of 26 postmortem findings of patients with COVID-19 in China. Kidney Int 2020, 98, 219-227, https://doi.org/10.1016/j.kint.2020.04.003.

17. Prayitno, A.; Oetari, R.A.; Shahiddin, I.; Elmanda, A.Y.; Septiarini, A.D.; Dharmayanti, L.; Saristiana Y.; Sari, Y. D. P. $\alpha$-Mangostin from Garcinia mangostana Linn and its Effect in Blood Insulin and Sugar Levels in Hyperglycemic Rat. J Clin Exp Invest 2021, 12. 1-10, https://doi.org/10.29333/jcei/9767.

18. Pahari, S.K.; Panda, S.; Manna, S.; Mukhopadhyaya, P.; Mahato, U.; Biswal, B. Development and validation of TLC of flavonoid from the ethanolic extract of plant enhydra fluctuans. J Drug Deliv Ther 2021, 11, 3641, https://doi.org/10.22270/jddt.v11i4-S.4915.

19. Dymek, A.; Mroczek, T. Methods of isolation and bioactivity of alkaloids obtained from selected species belonging to the Amaryllidaceae and Lycopodiaceae families. Curr Issues Pharm Med Sci 2021, 34, 81-84, https://doi.org/10.2478/cipms-2021-0016.

20. Jalil, M.T.M.; Zakaria, N.A.; Ibrahim, D. Effect of culture medium incorporated with ocimum sanctum extract in enhancing anti-mrsa activity of endophytic fungus, lasiodiplodia pseudotheobromae. J Pure Appl Microbiol 2021, 15, 1398-1408, https://doi.org/10.22207/JPAM.15.3.32. 
21. Bajkacz, S.; Ligor, M.; Baranowska, I.; Buszewski, B. Separation and determination of chemopreventive phytochemicals of flavonoids from brassicaceae plants. Mollecules 2021, 26, 1-17, https://doi.org/10.3390/molecules26164734.

22. Uddin, M.J.; Kim, E.H.; Hannan, M.; Ha, H. Pharmacotherapy against Oxidative stress in chronic kidney disease: Promising small molecule natural products targeting Nrf2-HO-1 signaling. Antioxidants 2021, 10, 126, https://doi.org/10.3390/antiox10020258.

23. Bulboacă, A.E.; Porfire, A.; Bolboacă, S.D.; Nicula, C.A.; Feștilă, D.G.; Roman, A.; Rajnoveanu, R.M.; Rajnoveanu, A.; Dogaru, G.; Boarescu, P.M.; Rus, V.; Bulboaca, C.A.; Bulboaca, A.I; Stănescu, I. Protective effects of liposomal curcumin on oxidative stress/antioxidant imbalance, metalloproteinases 2 and-9, histological changes and renal function in experimentalnephrotoxicity induced by gentamicin. Antioxidants 2021, 10, 1-17, https://doi.org/10.3390/antiox10020325.

24. Setianingsih, H.; Wisnumarta, S.E.; Tjandra, S.A. Repairing of renal tubules in diabetic rats (rattus norvegicus) diabetes after administration of golden sea cucumber (Stichopus hermanii). Pharmacogn Mag 2021, 13, 958-964, https://doi.org/10.5530/pj.2021.13.123.

25. Vien, L.C.; Chinnappan, S.; Mogana, R. Antioxidant activity of Garcinia mangostana L and alpha Mangostin : A Review. Res J Pharm Technol 2021, 14, 4466-4470, https://doi.org/10.52711/0974-360X.2021.00776.

26. Rusman, J.R.A.; Sundari, S.A.; Nuriliani, A.; Saragih, H.T. Ameliorative effect of Mangosteen (Garcinia mangostana L.) peel infusion on the histopathological structures of the liver and kidney of rats (Rattus norvegicus Berkenhout, 1769) after H2O2 induction. Vet World 2021, 14, 1578-1587, https://doi.org/10.14202/vetworld.2021.1579-1587. 